\title{
Surgical Site Infections in a Tertiary Referral Obstetric and Gynecologic Clinic Center in Istanbul and Review of the Literature
}

\author{
Hale GOKSEVER CELIK ${ }^{1}$, Engin CELIK ${ }^{2}$, Selin DIKMEN ${ }^{1}$, Merve KONAL ${ }^{1}$, Ali GEDIKBASI ${ }^{1}$ \\ Istanbul, Turkey
}

\section{ABSTRACT}

OBJECTIVE: The present study aimed to define characteristics of the patients who were readmitted with the diagnosis of surgical site infections after gynecologic or obstetric procedures and management of these patients. We also reviewed the literature in this context.

STUDY DESIGN: We examined 120 patients with surgical site infections that had been hospitalized and managed medically and/or surgically between April 2014 and April 2015. Characteristics of the patients were recorded and analyzed.

RESULTS: The mean age of the patients was $33.4 \pm 11.8$ years. The patients were readmitted for surgical site infections on the mean of $9.6 \pm 5.4$ days after the first operation. The most frequent procedures resulted with SSI were cesarean delivery, abdominal hysterectomy and vaginal birth. When patients were compared according to these procedures, there were statistically significant differences regarding age, gravida, parity, preoperative white blood cell count, postoperative white blood cell count and antibiotics usage.

CONCLUSION: Combining evidence-based surgical site infections prevention practices and clinician and patient cooperation will result in reduction in surgical site infections incidence following obstetric and gynecologic procedures. Because of economic burden and threat to the physical and psychological health of the patients, these modifiable risks should be recognized and surgical site infections should be minimized. After surgical site infections occurred, diagnosis and proper management with antibiotics and wound care with debridement and secondary suturing is important.

Keywords: Surgical site infections, Cesarean delivery, Hysterectomy, Vaginal birth

Gynecol Obstet Reprod Med 2018;24(1)37-41

\section{Introduction}

Surgical site infections (SSI) are infections that affect body tissues, cavities or organs manipulated in operation within 30 days after a surgical procedure. SSI are categorized by the US The Centers for Disease Control and Prevention National Healthcare Safety Network (CDC-NHSN) as superficial incisional, deep incisional and organ/space infections (1). The first type affects only the skin and/or subcutaneous tissue; the second type affects deep structures of the incision site (e.g. fascia

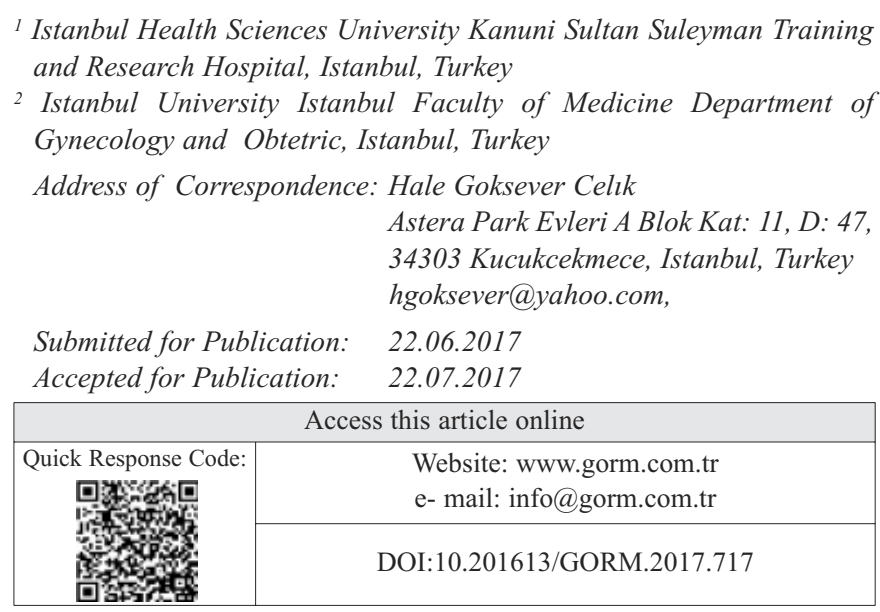

How to cite this article: Goksever Celik H. Celik E. Dikmen S. Konal M.Gedikbaşı A. VSurgical Site Infections in a Tertiary Referral Obstetric and Gynecologic Clinic Center in Istanbul and Review of the Literature. Gynecol Obstet Reprod Med 2018;24(1):37-41 and/or muscle layer); the last one affects any part of the anatomy which is manipulated during operation with the exception of a wall incision. There is purulent drainage with or without laboratory confirmation associated with localized swelling, redness and/or heat in the first two types of SSI. As the SSI deepen, systemic symptoms and signs appear such as fever $\left(>38^{\circ} \mathrm{C}\right)$, hypotension. Wound dehiscence refers to loss of integrity of the fascial closure.

Surgical site infections have the third highest incidence among the types of infections that necessitate hospitalization comprising $14-16 \%$ of total infections (2). SSI are frequently encountered as a postoperative complication after obstetric and gynecologic procedures. After childbirth, one of the most common reasons of prolonged hospital stay and readmission is the surgical site infections that are encountered 8-fold higher in cesarean delivery than vaginal birth $(3,4)$. The rate of SSI is higher among women who underwent abdominal hysterectomy compared with vaginal or laparoscopic hysterectomy (5). Unfortunately, incidence of SSI is likely underestimated because infections occur mostly after discharge and patients may present at outside clinics. Although the reported incidence decreases during last years because of widespread use of antibiotic prophylaxis prior to surgery and recognition of modifiable risk factors for SSI, it remains the most common complication of surgical procedures (6). 
Host risk factors for SSI are low socioeconomic status, malnutrition, obesity (high body mass index (BMI)), increased age, comorbidities such as diabetes mellitus, hypertension, chronic steroid use, cigarette smoking, preoperative anemia. There are surgical risk factors which are deficient prophylactic antibiotics administration, prolonged operation time, total blood loss $>1500 \mathrm{~mL}$ and blood transfusion, deficient preparation of the skin and vagina with chlorhexidine gluconate or povidone iodine, inappropriate wound closure (7).

Mostly isolated microorganisms after obstetric surgeries are Ureoplasma, coagulase negative staphylococci, Enterococcus faecalis, Mycoplasma, anaerobes, gram negative rods, Staphylococcus aureus and group B Streptococcus (8).

Early diagnosis and management of SSI are very important. When patients are discharged from hospital, they should be given clear-cut instructions about signs of SSI and encouraged to consult for evaluation. When diagnosed, antibiotics, wound exploration and debridement are the steps for SSI management.

The present study aimed to define characteristics of the patients who were readmitted with SSI after gynecologic and obstetric procedures and management of these patients. We also reviewed the literature in this context.

\section{Material and Method}

We examined 120 patients with SSI that had been hospitalized and managed medically or surgically between April 2014 and April 2015 in this retrospective cohort study. Patients treated as outpatient were excluded from this study. We collected data of the patients from the records in archive and we did not document any personal information. Informed consent had been taken from every patient about that medical information may be used in scientific publications.

One group of patients had been hospitalized and treated with only antibiotherapy and dressing. The other group needed surgical intervention in addition to antibiotherapy and dressing. In surgical approach, infected tissues had been debrided and sutured with permanent sutures after adequate dressing and antibiotics use.

Surgical site infections had been diagnosed and categorized according to CDC-NHSN as mentioned before. Age, BMI, gravidity and parity, operation history, any chronic illness, operation type and its indication, preoperative and postoperative hospital stay, antibiotics use, preoperative and postoperative intravenous iron supplementation or blood transfusion, any operation complication, readmission time for SSI from surgery, blood parameters and healing method were recorded. BMI was calculated as weight in kilograms over height in meters squared. BMI was categorized based on World Health Organization (WHO) classification into underweight (less than 18.5), normal weight (18.5-24.9), overweight (25-29.9), obese (>30) and morbid obese (>40).

\section{Statistical Analysis}

Statistical analysis were performed with SPSS software (Statistics Package for Social Sciences) version 20 for Windows. Difference in mean values and characteristics between groups is analyzed with independent samples $t$ test, chisquare test and one-way ANOVA test. Means were presented with standard deviation (SD). $p<.05$ was considered statistically significant.

\section{Results}

Surgical site infections were encountered mostly after the cesarean delivery, abdominal hysterectomy and vaginal birth (51.7\%, 32.5\% and $15.8 \%$, respectively). All patients had been consulted with stable vital signs on readmission. The mean age of the patients was $33.4 \pm 11.8$ years. The mean BMI of the patients was $29.9 \pm 5.4 \mathrm{~kg} / \mathrm{m}^{2}$. Most of the patients were multiparous (98.3\%), had no chronic illness (70.8\%) and no operation history $(68.3 \%)$. The mean hospitalization period of the patients $1.0 \pm 0.4$ days preoperatively, $2.3 \pm 1.2$ days postoperatively. The patients consulted with SSI on the mean of $9.6 \pm 5.4$ days after the procedure. Prophylactic antibiotherapy had been applied most frequently during operation (54.2\%). Most of the patients had not taken intravenous iron supplementation or blood transfusion before the operation. Management of SSI with only antibiotherapy was enough in $75 \%$ of cases because SSI had been superficial SSI according to CDC guidelines (Table 1). The mean CRP level on readmission was $107.9 \pm 88.8$. The mean values of blood parameters on readmission with SSI were shown on table 2.

When patients were compared according to the most frequent procedures associated with SSI (Table 3), age, gravida, parity, preoperative white blood cell (WBC) count, postoperative WBC count and antibiotics usage were different between groups as statistically significant. Patients who gave birth by vaginal route or cesarean section had higher preoperative white blood cell count before and after the birth. Patients underwent abdominal hysterectomy were hospitalized in a longer time both preoperatively and postoperatively comparing the other two procedures. Antibiotics had been prescribed mostly during the operation in cesarean delivery cases, whereas they were applied before and after the operation in abdominal hysterectomy cases. The mostly preferred regimens were cefazolin and/or cefoxitin and/or cefuroxime. The management of SSI did not differ between different procedures.

On consultation with SSI, there was not any statistical significant difference between groups regarding blood parameters on readmission (table 4). patients had lost more blood after abdominal hysterectomy comparing to the other two procedures.

Surgical site infections have been encountered in $1.02 \%$ of all cesarean deliveries (62/6074), 5.5\% of all abdominal hysterectomies (28/505), $0.19 \%$ of all vaginal births (19/9511) during this period. 
Table 1: Mean values with minimum and maximum values of all patients readmitted with surgical site infections

\begin{tabular}{|c|c|c|c|}
\hline \multicolumn{2}{|l|}{ Characteristics } & Mean values \pm standard deviation & Min-Max values \\
\hline \multicolumn{2}{|l|}{ Age (years) } & $33.4 \pm 11.8$ & $17-71$ \\
\hline \multicolumn{2}{|l|}{ Body mass index $\left(\mathrm{kg} / \mathrm{m}^{2}\right)$} & $29.9 \pm 5.4$ & $17.6-42.5$ \\
\hline \multicolumn{2}{|l|}{ Gravida } & $2.9 \pm 2.3$ & $0-11$ \\
\hline \multicolumn{2}{|l|}{ Parity } & $2.2 \pm 1.6$ & $0-10$ \\
\hline \multicolumn{2}{|l|}{ Preoperative hospitalization (days) } & $1.0 \pm 0.4$ & $0-24$ \\
\hline \multicolumn{2}{|c|}{ Postoperative hospitalization (days) } & $2.3 \pm 1.2$ & $1-9$ \\
\hline \multirow{2}{*}{\multicolumn{2}{|c|}{ Readmission time with SSI from surgery (days) }} & $9.6 \pm 5.4$ & $3-28$ \\
\hline & & n (\%) & \\
\hline \multirow{3}{*}{ Antibiotics usage } & Preoperative & $34(28.3)$ & \\
\hline & Intraoperative & $65(54.2)$ & \\
\hline & Postoperative & $39(32.5)$ & \\
\hline \multirow{2}{*}{ Intravenous iron supplementation } & Preoperative & 0 & \\
\hline & Postoperative & $4(3.3)$ & \\
\hline \multirow{2}{*}{ Blood transfusion } & Preoperative & $5(4.2)$ & \\
\hline & Postoperative & $7(5.8)$ & \\
\hline \multirow{2}{*}{ Management } & Only antibiotherapy & $90(75)$ & \\
\hline & Antibiotherapy+surgery & $30(25)$ & \\
\hline
\end{tabular}

Table 2: The mean values of blood parameters on readmission

\begin{tabular}{llrr}
\hline & Blood parameters & Mean values \pm SD & Min-Max values \\
\hline On readmission & Hemoglobin $(\mathrm{g} / \mathrm{dL})$ & $10.6 \pm 1.6$ & $6.2-13.6$ \\
& Hematocrit $\%)$ & $32.8 \pm 4.7$ & $19.9-43.0$ \\
White blood cell count $(103$ cells $/ \mu \mathrm{L})$ & $13.2 \pm 5.4$ & $4.9-38$ \\
Platelet count $(103$ cells $/ \mu \mathrm{L})$ & $380.5 \pm 122.3$ & $149.0-754.1$ \\
CRP & $107.9 \pm 88.8$ & $2.3-348.8$ \\
\hline
\end{tabular}

$S D$ : Standard deviation, CRP: C-reactive protein

Table 3: Comparison of the patients in different procedures according to clinical and demographic characteristics

\begin{tabular}{|c|c|c|c|c|c|c|c|}
\hline \multicolumn{2}{|l|}{ Characteristics } & $\begin{array}{l}\text { Cesarean } \\
\text { delivery } \\
\text { (CD) }(n: 62)\end{array}$ & $\begin{array}{l}\text { Abdominal } \\
\text { Hysterecto } \\
\text { my } \\
\text { (AH) (n:39) }\end{array}$ & $\begin{array}{l}\text { Vaginal } \\
\text { birth (VB) } \\
(\mathrm{n}: 19)\end{array}$ & $\begin{array}{l}\text { p value } \\
\text { (CD vs } \\
\text { VB) }\end{array}$ & $\begin{array}{l}\text { p value } \\
\text { (CD vs } \\
\text { AH) }\end{array}$ & $\begin{array}{l}\text { p value } \\
\text { (VB vs } A H \text { ) }\end{array}$ \\
\hline \multicolumn{2}{|l|}{ Age } & $27.7 \pm 5.3$ & $47.6 \pm 8.4$ & $22.9 \pm 4.7$ & 0.001 & $<0.001$ & $<0.001$ \\
\hline \multicolumn{2}{|l|}{ BMI $\left(\mathrm{kg} / \mathrm{m}^{2}\right)$} & $29.2 \pm 5.4$ & $30.7 \pm 5.4$ & $30.3 \pm 5.1$ & NS & NS & NS \\
\hline \multicolumn{2}{|l|}{ Gravida } & $2.1 \pm 1.3$ & $4.8 \pm 2.7$ & $1.4 \pm 0.8$ & 0.004 & $<0.001$ & $<0.001$ \\
\hline \multicolumn{2}{|l|}{ Parity } & $1.9 \pm 1.2$ & $3.2 \pm 2.0$ & $1.2 \pm 0.5$ & 0.001 & 0.001 & $<0.001$ \\
\hline \multicolumn{2}{|c|}{ Preoperative hospitalization (days) } & $0.9 \pm 3.2$ & $1.4 \pm 1.3$ & $0.4 \pm 0.3$ & NS & NS & 0.001 \\
\hline \multicolumn{2}{|c|}{ Postoperative hospitalization (days) } & $2.4 \pm 1.1$ & $2.6 \pm 1.2$ & $1.1 \pm 0.3$ & $<0.001$ & NS & $<0.001$ \\
\hline \multicolumn{2}{|c|}{ Readmission time with SSI from surgery (days) } & $9.7 \pm 4.9$ & $10.9 \pm 6.4$ & $6.4 \pm 2.6$ & 0.007 & NS & $<0.001$ \\
\hline \multirow[t]{2}{*}{ Management } & Only antibiotherapy & $49(79)$ & $27(69.2)$ & $14(73.7)$ & \multirow{2}{*}{ NS } & \multirow{2}{*}{ NS } & \multirow{2}{*}{ NS } \\
\hline & Antibiotherapy+surgery & $13(21)$ & $12(30.8)$ & $5(26.3)$ & & & \\
\hline \multirow[t]{2}{*}{ Preoperative AB usage } & Absent & $59(95.2)$ & $8(20.5)$ & $19(100)$ & \multirow{2}{*}{ NS } & \multirow{2}{*}{$<0.001$} & \multirow{2}{*}{$<0.001$} \\
\hline & Present & $3(4.8)$ & $31(79.5)$ & 0 & & & \\
\hline \multirow[t]{2}{*}{ Intraoperative $A B$ usage } & Absent & $11(17.7)$ & $26(66.7)$ & $18(94.7)$ & \multirow{2}{*}{$<0.001$} & \multirow{2}{*}{$<0.001$} & \multirow{2}{*}{0.019} \\
\hline & Present & $51(82.3)$ & $13(33.3)$ & $1(5.3)$ & & & \\
\hline \multirow[t]{2}{*}{ Postoperative $A B$ usage } & Absent & $50(80.6)$ & $12(30.8)$ & $19(100)$ & \multirow{2}{*}{0.038} & \multirow{2}{*}{$<0.001$} & \multirow{2}{*}{$<0.001$} \\
\hline & Present & $12(19.4)$ & $27(69.2)$ & 0 & & & \\
\hline
\end{tabular}

$C D$ : Cesarean delivery, AH: Abdominal hysterectomy, VB: Vaginal birth, BMI: Body mass index, SSI: Surgical site infections, AB: Antibiotics, NS: Non-significant 
Table 4: Comparison of the patients in different procedures according to blood parameters

\begin{tabular}{|c|c|c|c|c|c|c|c|}
\hline \multicolumn{2}{|l|}{ CHARACTERISTICS } & $\begin{array}{l}\text { Cesarean } \\
\text { delivery (CD) } \\
(\mathrm{n}: 62)\end{array}$ & $\begin{array}{l}\text { Abdominal } \\
\text { Hysterectomy } \\
(\mathrm{AH})(\mathrm{n}: 39)\end{array}$ & $\begin{array}{l}\text { Vaginal birth } \\
\text { (VB) }(\mathrm{n}: 19)\end{array}$ & $\begin{array}{l}\text { p value } \\
\text { (CD vs } \\
\text { VB) }\end{array}$ & $\begin{array}{l}\mathrm{p} \text { value } \\
\text { (CD vs } \\
\mathrm{AH})\end{array}$ & $\begin{array}{l}\mathrm{p} \text { value } \\
\text { (VB vs } \\
\mathrm{AH} \text { ) }\end{array}$ \\
\hline \multicolumn{2}{|c|}{ Preoperative WBC count (103 cells/ $\mu \mathrm{L}$ ) } & $12.8 \pm 4.4$ & $8.3 \pm 2.4$ & $12.9 \pm 3.5$ & NS & $<0.001$ & $<0.001$ \\
\hline \multicolumn{2}{|c|}{ Preoperative Platelet count (103 cells/ $\mu \mathrm{L}$ ) } & $218.2 \pm 74.8$ & $299.1 \pm 108.6$ & $259.2 \pm 87.8$ & NS & $<0.001$ & NS \\
\hline \multicolumn{2}{|c|}{ Postoperative WBC count (103 cells/ $\mu \mathrm{L})$} & $15.2 \pm 4.7$ & $12.5 \pm 3.1$ & $18.6 \pm 6.3$ & 0.020 & 0.011 & $<0.001$ \\
\hline \multicolumn{2}{|c|}{ Postoperative Platelet count (103 cells/ $\mu \mathrm{L})$} & $206.0 \pm 72.4$ & $250.6 \pm 72.0$ & $244.9 \pm 77.3$ & NS & 0.011 & NS \\
\hline \multirow[t]{4}{*}{ On readmission } & Hemoglobin (g/dL) & $10.7 \pm 1.5$ & $10.3 \pm 1.6$ & $10.6 \pm 1.7 \mathrm{NS}$ & NS & NS & NS \\
\hline & Hematocrit (\%) & $33.3 \pm 4.7$ & $31.7 \pm 4.4$ & $33.2 \pm 5.4$ & NS & NS & NS \\
\hline & White blood cell (103 cells/ $\mu \mathrm{L})$ & $12.9 \pm 4.3$ & $12.5 \pm 6.6$ & $15.2 \pm 5.8$ & NS & NS & NS \\
\hline & Platelet count (103 cells/ $\mu \mathrm{L})$ & $122.0 \pm 98.1$ & $372.1 \pm 127.6$ & $368.0 \pm 118.2$ & NS & NS & NS \\
\hline \multicolumn{2}{|l|}{ CRP level } & $122.0 \pm 98.8$ & $103.7 \pm 81.3$ & $70.3 \pm 53.0$ & 0.004 & NS & NS \\
\hline \multirow{2}{*}{$\begin{array}{l}\text { Postoperative } \\
\text { Hemoglobin decline }\end{array}$} & $<1 \mathrm{~g} / \mathrm{dl}$ & $39(62.9)$ & $14(35.9)$ & $8(42.1)$ & \multirow{2}{*}{ NS } & \multirow{2}{*}{0.008} & \multirow{2}{*}{ NS } \\
\hline & $\geq 1 \mathrm{~g} / \mathrm{dl}$ & $23(37.1)$ & $25(64.1)$ & $11(57.9)$ & & & \\
\hline \multirow{2}{*}{$\begin{array}{l}\text { Postoperative } \\
\text { Hematocrit decline }\end{array}$} & $<3 \%$ & $38(61.3)$ & $13(33.3)$ & $7(36.8)$ & \multirow{2}{*}{ NS } & \multirow{2}{*}{0.006} & \multirow{2}{*}{ NS } \\
\hline & $\geq 3 \%$ & $24(38.7)$ & $26(66.7)$ & $12(63.2)$ & & & \\
\hline
\end{tabular}

CD: Cesarean delivery, AH: Abdominal hysterectomy, VB: Vaginal birth, WBC: White blood cell, CRP: C-reactive protein, NS: Non-significant

\section{Discussion}

Surgical site infections is an important postoperative complication that is associated with significant morbidity and mortality. Many studies reported that the incidence of SSI in developing countries is higher than in developed countries. Mpogoro et al associated this complication with standard of hygiene practiced in developed countries (9).

Predictors for SSI have been investigated in many studies in which reproductive age group between 20 and 35 years, high BMI, malnutrition, low socioeconomic status, preoperative anemia and comorbidities such as diabetes mellitus, hypertension are defined as risk factors for SSI. Cinar et al also determined that younger age and obesity are independent risk factors for post-cesarean SSI (10). Modifiable risk factors are associated with surgical procedure itself among which prophylactic antibiotics use is the most important one (6). The American College of Obstetricians and Gynecologists (ACOG) defined some criteria for antibiotics prophylaxis (11). According to this guideline, there is no need to administer antibiotics at vaginal birth under normal conditions, so we did not apply prophylactic antibiotics for vaginal birth. The most convenient time to administer antibiotic prophylaxis is in the operating suite, just before induction of anesthesia. So we generally applied prophylactic antibiotherapy mostly after the operation begun $(54.2 \%)$. We have applied antibiotherapy intraoperatively in cesarean delivery, preoperatively and postoperatively in hysterectomy compatible with this guideline that offers second dose if the operation takes longer than 3 hours or if the blood loss is more than $1500 \mathrm{ml}$. Our hospital is a tertiary referral center and so mostly complicated hysterectomy cases are taken into operation and the recurrent dosages of an- tibiotics are applied. We get culture from all cases that are hospitalized for SSI and the treatment is planned according to these results, but we did not reach all culture results due to lack of records. Similarly, we did not evaluate operation time and intraoperative blood loss. If postoperative intravenous iron supplementation or blood transfusion is accepted to reflect intraoperative blood loss, there was not any difference between all procedures according to our results. Interestingly higher preoperative and postoperative WBC count and platelet count were found in patients who gave birth by both routes. Because inappropriate skin preparation before surgery is found as a risk factor for SSI, we have been preparing skin with chlorhexidine in all operations, so this did not make a difference in our results.

The mostly encountered operation in SSI was cesarean delivery because of high incidence. Schneid-Kofman et al also found emergency cesarean delivery resulted in SSI more frequently (12). Although there is no need for antibiotic prophylaxis at vaginal birth according to guidelines, SSI may be experienced on episiotomy as we have seen in our results. Therefore, patients should be cautioned about this condition.

The reason for higher association between abdominal hysterectomy and SSI was thought that our center is a tertiary referral center, so more difficult cases are referred to our clinics. These operations are taken longer; more blood loss is happened.

Predictors for SSI are modifiable, so these infections may be prevented. Based on CDC guidelines, best practices are defined currently. Hair at the incision site should be clipped only if necessary. Antibiotics should be administered prophylactically within 30 minutes before surgical procedure and repeat 
after $1500 \mathrm{~mL}$ blood loss or at 3 hours of operating time. Skin should be prepared with chlorhexidine. Surgical team should wash their hands and forearms in good condition. Comorbidities should be controlled such as blood glucose in diabetic patients. In patients with high BMI, especially if subcutaneous tissue layer $>2 \mathrm{~cm}$ in depth, we should close with sutures and/or use closed suction draining (13). Diet with appropriate caloric intake should be remembered for perfect wound healing (14).

Because of economic burden and threat to the physical and psychological health of the patients, these modifiable risks should be recognized and SSI should be minimized (15). After SSI occurred, diagnosis and proper management with antibiotics and wound care with debridement and secondary suturing if necessary. Combining evidence based SSI prevention practices and clinician and patient cooperation will result in reduction in SSI incidence following obstetric and gynecologic operations.

: There are no conflicts of interest in connection with this article. There was no specific funding for this study.

\section{References}

1. Centers for Disease Control (CDC) Surgical Site Infection (SSI) Event. Available at: http://www.cdc.gov/nhsn/ pdfs/ pscmanual/9pscssicurrent.pdf. Accessed March 26, 2014.

2. Madeira MZ, Trabasso P. Surgical site infections in women and their association with clinical conditions. Rev Soc Bras Med Trop 2014 Jul;47(4):457-61.

3. Axelsson D, Blomberg M. Prevalence of postpartum infections: a population-based observational study. Acta Obstet Gynecol Scand 2014 Oct;93(10):1065-8.

4. Shrestha S, Shrestha R, Shrestha B, Dongol A. Incidence and risk factors of surgical site infection following cesarean section at Dhulikhel Hospital. Kathmandu Univ Med J 2014 Apr-Jun;12(46):113-6.

5. Mahdi H, Goodrich S, Lockhart D, DeBernardo R, Moslemi-Kebria M. Predictors of surgical site infection in women undergoing hysterectomy for benign gynecologic disease: a multicenter analysis using the national surgical quality improvement program data. J Minim Invasive
Gynecol 2014 Sep-Oct;21(5):901-9.

6. Lachiewicz MP, Moulton LJ, Jaiyeoba O. Pelvic surgical site infections in gynecologic surgery. Infect Dis Obstet Gynecol. 2015; 2015:614950. doi: 10.1155/2015/614950.

7. Corcoran S, Jackson V, Coulter-Smith S, Loughrey J, McKenna P, Cafferkey M. Surgical site infection after cesarean section: implementing 3 changes to improve the quality of patient care. Am J Infect Control 2013 Dec; 41(12):1258-63.

8. Roberts S, Maccato M, Faro S, Pinell P. The microbiology of post-cesarean wound morbidity. Obstet Gynecol 1993; 81:383-6.

9. Mpogoro FJ, Mshana SE, Mirambo MM, Kidenya BR, Gumodoka B, Imirzalioglu C. Incidence and predictors of surgical site infections following caesarean sections at Bugando Medical Centre, Mwanza, Tanzania. Antimicrob Resist Infect Control 2014 Aug 11;3:25.

10. Cinar M, Timur H, Guzel AI, Tokmak A, Ersak B, Saygan $\mathrm{S}$, et al. The association between preterm premature rupture of membranes and surgical site infection following cesarean section. Gynecol Obstet Reprod Med 2016; 22(3):139-143.

11. ACOG Practice Bulletin No.120: Use of prophylactic antibiotics in labor and delivery. Obstet Gynecol 2011; 117(6):1472-83.

12. Schneid-Kofman N, Sheiner E, Levy A, Holcberg G. Risk factors for wound infection following cesarean deliveries. Int J Gynaecol Obstet 2005 Jul;90(1):10-5.

13. Witter FR, Lawson P, Ferrell J. Decreasing cesarean section surgical site: An ongoing comprehensive quality improvement program. Am J Infect Control 2014 Apr; 42(4): 429-31.

14. Fitzwater JL, Tita AT. Prevention and management of cesarean wound infection. Obstet Gynecol Clin North Am 2014 Dec;41(4):671-89.

15. Riley MM, Suda D, Tabsh K, Flood A, Pegues DA. Reduction of surgical site infections in low transverse cesarean section at a university hospital. Am J Infect Control 2012 Nov;40(9):820-5. 